\title{
Maternal gaze to the infant face: effects of infant age and facial configuration during mother-infant engagement in the first nine weeks
}

Article

Accepted Version

Creative Commons: Attribution-Noncommercial-No Derivative Works 4.0

De Pascalis, L., Kkeli, N., Chakrabarti, B., Dalton, L., Vaillancourt, K., Rayson, H., Bicknell, S., Goodacre, T., Cooper, P., Stein, A. and Murray, L. (2017) Maternal gaze to the infant face: effects of infant age and facial configuration during mother-infant engagement in the first nine weeks. Infant Behavior and Development, 46. pp. 91-99. ISSN 0163-6383 doi: https://doi.org/10.1016/j.infbeh.2016.12.003 Available at https://centaur.reading.ac.uk/68638/

It is advisable to refer to the publisher's version if you intend to cite from the work. See Guidance on citing.

Published version at: http://dx.doi.org/10.1016/j.infbeh.2016.12.003

To link to this article DOI: http://dx.doi.org/10.1016/j.infbeh.2016.12.003

Publisher: Elsevier

All outputs in CentAUR are protected by Intellectual Property Rights law, including copyright law. Copyright and IPR is retained by the creators or other copyright holders. Terms and conditions for use of this material are defined in the End User Agreement. 


\section{www.reading.ac.uk/centaur}

\section{CentAUR}

Central Archive at the University of Reading

Reading's research outputs online 
Maternal gaze to the infant face: effects of infant age and facial configuration during mother-infant engagement in the first nine weeks

Leonardo De Pascalis $^{\mathrm{a}, \mathrm{b}}$, Natalie Kkeli ${ }^{\mathrm{c}}$, Bhismadev Chakrabarti ${ }^{\mathrm{a}}$, Louise Dalton ${ }^{\mathrm{d}}$, Kyla Vaillancourt $^{\mathrm{e}}$, Holly Rayson ${ }^{\mathrm{a}}$, Sarah Bicknell ${ }^{\mathrm{a}}$, Tim Goodacre ${ }^{\mathrm{d}}$, Peter Cooper ${ }^{\mathrm{a}, \mathrm{f}, \mathrm{g}}$ Alan Stein ${ }^{\mathrm{h}, \mathrm{i}}$, Lynne Murray a,f,g

${ }^{\text {a }}$ School of Psychology and Clinical Language Sciences, University of Reading, United Kingdom.

${ }^{\mathrm{b}}$ Institute of Psychology, Health and Society, University of Liverpool, United Kingdom.

${ }^{\mathrm{c}}$ University of Cyprus, Nicosia, Cyprus.

${ }^{\mathrm{d}}$ Spires Cleft Centre, John Radcliffe Hospital, Oxford, United Kingdom.

e Institute of Psychiatry, Psychology and Neuroscience, King's College London, United Kingdom.

${ }^{\mathrm{f}}$ Department of Psychology, Stellenbosch University, South Africa.

${ }^{\mathrm{g}}$ Department of Psychology, University of Cape Town, South Africa.

${ }^{\mathrm{h}}$ Section of Child and Adolescent Psychiatry, Department of Psychiatry, University of Oxford, United Kingdom.

${ }^{\text {i }}$ School of Public Health, University of Witwatersrand, Johannesburg, South Africa.

Correspondence to: Lynne Murray, School of Psychology and Clinical Language Sciences, University of Reading, Reading RG6 6AL, UK. Telephone: +44 (0) 118378 6302. E-mail: lynne.murray@reading.c.uk 


\begin{abstract}
Background: Adult gaze plays an important role in early infant development, and infants are highly sensitive to its presence and direction. Little is known, however, about how adults look at infants while interacting with them. Using eye-tracking technology, this study investigated maternal gaze during naturalistic interactions, and how it was influenced by infant age, focusing on the transition from the first to the second month when social expressiveness emerges, and by infant facial configuration, focusing on the effect of cleft lip.
\end{abstract}

Methods: Thirty infants (10 with a cleft lip), and their mothers, were seen at 1, 3, 5, 7, and 9 weeks. Mothers were asked to interact with their infants while wearing eye-tracking glasses. Fixation duration and count were calculated for general (infant face, body, and surrounding environment), and infant facial (eyes, mouth, other) areas.

Results: At all ages, mothers gazed almost exclusively towards their infant's face, but this was reduced in the presence of a cleft lip. Within the infant's face, the eyes attracted the greatest attention, for all mothers, at all ages. From the first to the second month, all mothers increased their visual attention towards their infant's mouth. Regardless of infant age, the presence of a cleft lip was associated with decreased maternal gaze to the infant's mouth.

Conclusions: This study provides novel findings concerning maternal gaze to infant faces during naturalistic interactions. Maternal gaze changes with infant age, in line with established shifts in social development, and according to infant facial configuration. Decreased gaze to the mouth area associated with infant cleft lip might affect maternal responsiveness, and suggests new dimensions to target in supporting these mothers.

Keywords: Mother-infant interaction; Gaze; Cleft lip/palate; Infancy; Face perception 


\section{Introduction}

Infants are highly sensitive to adult faces, and particularly to their gaze (see Johnson, Senju, \& Tomalski, 2015; Simion \& Di Giorgio, 2015, for reviews). Even in the newborn period, infants prefer face-like to non-face-like visual arrays (Johnson, Dziurawiec, Ellis, \& Morton, 1991), and are attracted to a prototypical eye-contact stimulus, as evidenced by their preference for faces that are upright vs. upside down (Grossmann, Johnson, Farroni, \& Csibra, 2007), with eyes open vs. shut (Batki, Baron-Cohen, Wheelwright, Connellan, \& Ahluwalia, 2000), facing forward vs. being averted (Farroni, Csibra, Simion \& Johnson, 2002), and with the normal contrast-polarity (dark iris on white sclera) vs. reversed (Farroni et al., 2005).

Notably, infant sensitivity to faces and gaze direction rapidly acquires functional significance. Thus, within the first two-three months of life, adult direct gaze enhances infant facial processing and recognition (Farroni, Massaccesi, Menon, \& Johnson, 2007; Rigato, Menon, Johnson, Faraguna, \& Farroni, 2011), activating similar neural structures to those of adults in response to communicative signals (the right superior posterior temporal cortex and the right fronto-polar cortex, see Grossmann et al., 2008). Adult direct gaze also increases engagement during early face-to-face interactions (Arco, Self, \& Gutrecht, 1979; Delgado, Messinger, \& Yale, 2002; Stern, 1974; Symons, Hains, \& Muir, 1998), reinforcing early social expressiveness in human (Bloom, 1974; Hains \& Muir, 1996), and primate infants (Ferrari, Paukner, Ionica, \& Suomi, 2009). The degree of mutual gaze during early interactions, listed among the innate releasers of caretaking maternal responses (Robson, 1967), has been found to predict better mother-infant relationship quality (Britton, Gronwaldt, \& Britton, 2001), disturbances in which can have detrimental effects on child developmental outcomes (Murray, Fiori-Cowley, Hooper, \& Cooper, 1996; Landry, Smith, \& Swank, 2006). By four-five months, infants can detect lateral changes in gaze direction as 
small as five degrees (Symons et al., 1998), and sensitivity to such shifts, when preceded by cues like direct gaze, underpins the reorientation of infant attention to a focus of potential joint interest (Farroni, Mansfield, Lai, \& Johnson, 2003; Senju \& Csibra, 2008), a capacity that is foundational for later social skills and understanding (Baron-Cohen, 1994; Gómez, 2009).

Given the volume of largely experimental evidence concerning infant sensitivity to adult faces, and in particular the early preference for direct gaze, it is striking that relatively little is known about how adults actually look at infants during their contacts with them. Important questions, therefore, are first, whether infant predispositions are matched by specific patterns of parental gaze towards them, including whether gaze to particular areas of the face is privileged, and second, whether certain infant characteristics influence adult gaze.

Two infant characteristics that could influence adult gaze are age and facial configuration. Regarding age, a key developmental change that might influence adult gaze direction is the onset, from around six weeks, of active social expressiveness, such as smiles, vocalisations and active communicative mouthing, or 'prespeech' (Lavelli \& Fogel, 2002; Trevarthen, 1979). In adult-adult interactions, gaze direction shifts according to listener/speaker roles: when speaking, gaze is directed to the other adult's eyes at the start and end of speaking periods (shifting away and then briefly back to the listener's eyes in the intervening time); during listening, however, gaze is predominantly directed to the other's mouth (Buchan, Paré, \& Munhall, 2007; Paré, Richler, ten Hove, \& Munhall, 2003). Parent-infant interactions differ from those between adults: adult gaze away from the infant's whole face area is rare (less than $10 \%$ of time, see Murray et al., 2008) and almost always precipitated by the infant's breaking gaze (Stern, 1974). Moreover, the persistence of adult gaze to the infant's face is constant across contexts: for example, although adults show different behavioural patterns during playful engagements and feeding interactions, (including greater use of 
vocalisations in the former than in the latter), gaze to the infant's face remains predominant throughout both kinds of interaction (Stern, 1977). Notwithstanding the overall prominence of gaze to the infant's face, exactly where on the face mothers look is unclear. Nevertheless, it can be hypothesised that, if maternal gaze is sensitive to the developmental shift to active infant communication from six weeks, there should be an increasing focus on the infant's mouth after this period, and reduced gaze to eyes and other facial areas. As Leeb \& Rejskind (2004) have noted, most studies on eye-contact in mother-infant interactions have not made such distinctions, studying gaze only to the infant's whole face area. This is mainly due to difficulty in precisely coding gaze direction in an area as small as an infant's face, without employing assessment paradigms disruptive of the naturalistic nature of mother-infant interactions. Recent eye tracking technology, however, now makes it possible to address this question.

The second infant characteristic that might influence adult gaze responses is facial configuration. Infant faces have special characteristics referred to as 'cute'-i.e., wide brow, chubby cheeks, small nose and mouth, large eyes positioned half way down the head (Parsons, Young, Murray, Stein, \& Kringelbach, 2010), which evoke positive responses, and caretaking motivation in adults (Glocker et al., 2009). The more an infant's face deviates from this configuration, even within typical infant samples, the less cute adults tend to rate them (Glocker et al., 2009). In populations with craniofacial abnormalities, the specific facial morphology of infant 'cuteness' is disturbed, with infants with cleft lip, for example, being generally rated by naïve observers as being less cute than typical infants (Parsons et al., 2011; Rayson et al., in press; Yamamoto, Ariely, Chi, Langleben, \& Elman, 2009). Notably, the facial disruption entailed by cleft lip also reduces the specific parental brain responses elicited by typical infant faces and associated with reward (Kringelbach et al., 2008; Parsons et al., 2013). With regard to how gaze to faces might be affected by such a change in 
morphology, three studies have been conducted comparing responses to static images of individuals with and without cleft lip. Two studies compared gaze to typical adult faces compared to adult faces with repaired cleft lip (Meyer-Marcotty, Gerdes, Reuther, StellzigEisenhauer, \& Alpers, 2010; Meyer-Marcotty, Gerdes, Stellzig-Eisenhauer, \& Alpers, 2011), while another study concerned adults' gaze to either typical infant faces, or infant faces with unrepaired cleft lip (Rayson et al., in press). These studies found the presence of cleft lip to affect gaze, with increased gaze towards the mouth region, at the expense of gaze towards the eyes. However, given the experimental nature of these studies, and the use of static facial images, it is unclear whether this effect of disrupted facial configuration on adult gaze extends to naturally occurring interactions and, in particular, to those between infants and parents. Studies of parent-infant interactions in the context of cleft lip have found reduced gaze towards the infant (Montirosso et al., 2012; Murray et al., 2008), but gaze direction was not rated precisely, and no evidence is available on gaze to specific face regions.

The current study addressed these issues and, specifically, the following questions (i) which areas of infant faces attract maternal gaze; ii) what are the effects on adult gaze of the change in infant social development at six weeks, and (iii) what are the effects on parental gaze of the structural alteration in infant facial configuration represented by a cleft lip. We investigated these questions by conducting a naturalistic study of maternal gaze during interactions with their infants through the first nine weeks of life in a sample that included both typical infants and infants with cleft lip. During the interactions, mothers wore eye-tracking glasses that allowed identification of the precise area of the infant's face to which gaze was directed. Based on previous research showing early infant preference for direct gaze, we predicted that mothers would, overall, prioritise looking at infant eyes compared to other face areas, but that fixations on the mouth would increase after six weeks; we also predicted that, compared with mothers of typical infants, mothers of infants with cleft lip would fixate on the mouth region, 
at the expense of typical levels of fixation on infant eyes.

\section{Method}

\section{Procedure}

The index group was recruited at the Spires Cleft Centre, Oxford, UK, and comprised infants with cleft lip, with or without cleft palate. Following diagnosis, the mothers were approached by a Clinical Nurse Specialist from the cleft team, either antenatally (the diagnosis is usually made at the 20-week antenatal ultrasound scan) or postnatally. The cleft nurse informed the families about the study and, with parental agreement, passed the details of the family to the research team.

The comparison group of typical infants was recruited postnatally through the Child Development Group Database of the School of Psychology of the University of Reading, which holds the details of those mothers who, recruited on the delivery ward at the Royal Berkshire Hospital, express an interest in taking part in child development research. Infants with additional congenital disorders were excluded. At weeks 1, 3, 5, 7, and 9 postpartum, families were visited at home by a female researcher. When infants were alert and contented, they were placed semi-reclined on their back, with the mother seated opposite, leaning over them, a positioning previously shown to maximise mother-infant engagement (Lavelli \& Fogel, 2002). The mother was asked to engage with her infant, as she would usually do, without using toys, in a room where the two could do so undisturbed, while the researcher unobtrusively monitored the situation. During the interaction mothers wore a mobile eye tracker system, recording their gaze (Tobii Glasses 1 Eye Tracker, by Tobii Technology, Stockholm, Sweden). (see Supplementary Materials for details). 
Mothers provided written informed consent. The study was approved by the NHS Research Ethics Committee (No. 11/SC/0242), and the University of Reading Ethics Committee (No. $11 / 45)$.

\section{Measures}

Two sets of gaze data were analysed. The first concerned maternal fixations to General Areas of Interest (AOIs): the infant's face as a whole, the rest of their body, and the surrounding area. For this analysis, the whole duration of the eye tracking footage was used.

The second dataset concerned maternal fixations specifically within the infant's facial area, during segments where the whole face of the infant was visible for at least two seconds. Fixations were measured within three Facial AOIs: the eyes, the mouth, and the rest of the infant's face.

Both duration, and count of fixations within the AOIs were analysed, to ensure the results were not driven by any artefactual variability in either of these metrics (see Supplementary Materials for details).

\section{Data Analysis}

Because of variability in recording duration, data for fixation duration and count were transformed into percentages. For the general AOIs, each percentage represents how many times (count) and for how long (duration) mothers looked at each area, during the whole eyetracking recording, in relation to the overall number of fixations (for count), or the overall duration of the recording (for duration). For facial AOIs, during periods when the whole of the infant's face was visible, i.e., when there was face-to-face contact with the infant, each percentage represents how many times (count) and for how long (duration) mothers looked at 
each area, in relation to the total number of fixations to the whole face (for count), or the total duration of fixations (for duration).

To maximise reliability, we selected data for analysis using the precision estimate provided by the Tobii Glasses 1 Eye Tracker, with a 50\% threshold (eye-data was recorded at least 1 every 2 frames) (see Supplementary Materials for details).

Two separate sets of three-level random intercept mixed models (one for fixation duration, the other count) were used to test main effects of infant age (younger (weeks 1,3 and 5) vs. older (weeks 7 and 9), group (typical infant vs. infant with cleft lip) and either General AOI (Face vs. Body vs. No Infant), or Facial AOI (Mouth vs. Eyes vs. Other Facial Areas), as well as all two-way interactions. Three-way interactions were not tested due to sample size concerns (Heo \& Leon, 2010; Leon \& Heo, 2009). The models also included, as covariates, the main effects of demographic variables differing by group, as well as the main effect of a cleft severity score $(0=$ No Cleft, $1=$ Unilateral Cleft Lip, $2=$ Unilateral Cleft Lip and Palate, 3=Bilateral Cleft Lip, 4=Bilateral Cleft Lip and Palate). Likelihood Ratio Tests were used to assess the effect of predictors, and select the most parsimonious models fitting the data. False Discovery Rate corrections (Benjamini \& Hochberg, 1995) were used for multiple comparisons. A p-value $<0.05$ was considered significant.

\section{Results}

\section{Sample}

The sample comprised 30 mother-infant pairs, 10 index ( 2 males and 8 females) and 20 comparison (13 males and 7 females). All participants were retained in the study, but not all were available to complete all 5 assessments, with a $16.67 \%$ reduction in data available for week $1,13.33 \%$ for week 3 , and $6.67 \%$ for weeks 5,7 , and 9 . The mean (sd) number of assessments available per participant was 4.50 (0.63). No formal power calculation was 
performed, as no similar study has previously been conducted. Sample characteristics (see Table S1 in Supplementary Materials) were similar in terms of social class, education and ethnicity, although there were more married mothers in the comparison group vs. the index group ( $\mathrm{p}=.006)$; infant birth weight was higher in comparison vs. index infants $(\mathrm{p}=.015)$, and feeding method differed $(\mathrm{p}=.005)$ (more formula feeding in the index group). The two groups were also similar in terms of having scores in the non-clinical range on a measure of depressive symptomatology when assessed at week $9(\mathrm{t}(23)=-0.960, \mathrm{p}=.347)$, as measured using the Edinburgh Postnatal Depression Scale (Cox, Holden, \& Sagovsky, 1987) (M(sd): Index $=5.71(4.54) ;$ Comparison=4.11(3.43)).

General, and Facial AOIs were created by two trained researchers. A third trained coder created AOIs in a random sample of 35 recordings, derived from different time points, participants and raters, to establish inter-rater reliability. Inter-rater correlations for duration values within AOIs ranged between .94 and .96 , while those for count values ranged between .78 and .93 , showing good to excellent inter-rater reliability.

\section{General areas of fixation during mother-infant engagement}

The duration of eye-tracking footage analysed for mother-infant general engagement was similar in the two groups, with an overall mean of $\mathrm{M}(\mathrm{sd})=165.37(31.48)$ seconds.

\section{Fixation Count}

An effect of AOI emerged $(\mathrm{F}(2,210)=2649.972 ; \mathrm{p}<.001)$ : regardless of infant age and presence of a cleft lip, maternal gaze focused on the infant's face or body more frequently than on the rest of the environment (Body vs. No Infant: $p<0.001$; Face vs. No Infant: $\mathrm{p}<0.001$ ), with an almost exclusive focus on the infant's face (Face vs. Body: $p<0.001$ ) (Table 1). An interaction between AOI and Group was also found $(F(2,210)=6.671 ; p=.002)$, with 
index mothers looking less frequently at their infant's face $(\mathrm{p}=.013)$, and more frequently at their infant's body $(\mathrm{p}=.012)$, compared to those in the comparison group (Table 1).

\section{Fixation Duration}

An effect of AOI emerged $(F(2,210)=2611.489 ; p<.001)$, with maternal gaze focusing almost exclusively on the infant's face rather than their body or the surrounding environment (Face vs. Body: $p<0.001$; Face vs. No Infant: $p<0.001$; Body vs. No Infant: $p<0.001$ ) (Table 1). An interaction between AOI and Group also emerged $(\mathrm{F}(2,210)=6.946 ; \mathrm{p}=.001)$, with index mothers spending a shorter time looking at their infant's face $(\mathrm{p}=.011)$, and more time looking at their infant's body ( $\mathrm{p}=.010)$ (Table 1), compared to those in the comparison group.

\begin{tabular}{lllll}
\hline & & Face(\%) & Body $(\%)$ & Not Infant(\%) \\
Count & Index & $88.39 \pm 13.79$ & $11.21 \pm 13.35$ & $0.41 \pm 1.04$ \\
& & & & \\
& Comparison & $93.47 \pm 10.19$ & $6.24 \pm 10.04$ & $0.29 \pm 0.77$ \\
& & & & \\
Duration & Index & $88.20 \pm 13.94$ & $11.40 \pm 13.49$ & $0.40 \pm 1.03$ \\
& & & & $0.28 \pm 0.76$ \\
& Comparison & $93.42 \pm 10.20$ & $6.30 \pm 10.05$ & \\
\hline
\end{tabular}

Table 1: Fixation Count and Duration Percentages $(\mathrm{M} \pm \mathrm{sd})$, within General Areas, according to Group.

Facial areas of fixation during mother-infant face-to-face engagement

The duration of eye-tracking footage analysed for mother-infant face-to-face engagement did not differ by group, with an overall mean of $\mathrm{M}(\mathrm{sd})=16.00(15.87)$.

\section{Fixation Count}


An effect of $\mathrm{AOI}(\mathrm{F}(2,222)=91.147 ; \mathrm{p}<0.001)$ was found, showing that, regardless of infant age and presence of a cleft lip, the infant eye region was looked at more frequently compared to both the mouth area $(\mathrm{p}<.001)$ and the rest of the face $(\mathrm{p}<.001)$; and the eye region itself was looked at longer than the mouth area $(\mathrm{p}<.001)$. An interaction between AOI and Infant Age $(F(2,222)=10.557 ; \mathrm{p}<.001)$ was also found: from the younger to the older age, mothers looked with increasing frequency at their infant's mouth $(\mathrm{p}=.019)$, and decreasing frequency at facial areas other than eyes or mouth $(\mathrm{p}=.019)$, regardless of the presence of a cleft lip (Table 2). Finally, an interaction between AOI and Group was found $(\mathrm{F}(2,222)=5.922$; $\mathrm{p}=.003$ ): regardless of infant age, although index group mothers looked at their infant's eyes with similar frequency to those in the comparison group, they looked more frequently at facial areas other than eyes or mouth $(\mathrm{p}<.001)$, and they looked less frequently at their infant's mouth $(\mathrm{p}=.037)$ (Table 2).

\begin{tabular}{|c|c|c|c|c|}
\hline & & $\operatorname{Mouth}(\%)$ & $\operatorname{Eyes}(\%)$ & Other Facial Areas $(\%)$ \\
\hline \multirow[t]{2}{*}{ Infant Age } & < 6 weeks & $12.38 \pm 15.35$ & $59.23 \pm 22.88$ & $28.39 \pm 25.36$ \\
\hline & $>6$ weeks & $22.64 \pm 24.97$ & $59.06 \pm 25.98$ & $18.29 \pm 21.68$ \\
\hline \multirow[t]{2}{*}{ Group } & Index & $9.82 \pm 16.43$ & $54.31 \pm 26.11$ & $35.87 \pm 27.21$ \\
\hline & Comparison & $19.88 \pm 21.65$ & $61.21 \pm 23.17$ & $18.91 \pm 21.08$ \\
\hline
\end{tabular}

Table 2: Fixation Count Percentages $(\mathrm{M} \pm \mathrm{sd})$, within Facial Areas, according to Infant Age and Group.

Fixation Duration 
An effect of AOI emerged $(\mathrm{F}(2,222)=69.362 ; \mathrm{p}<.001)$, with mothers looking at their infant's eyes for a longer time compared to the mouth area $(\mathrm{p}<.001)$ and to the rest of the face $(\mathrm{p}<.001)$, and the latter being looked at for a longer time than the mouth $(\mathrm{p}<.001)$. An interaction between AOI and Infant Age $(F(2,222)=9.191 ; \mathrm{p}<.001)$ was also found. Regardless of the presence of cleft lip, there was an increase from the younger to the older age in the time mothers spent looking at their infant's mouth $(\mathrm{p}=.033)$, and a marginally significant decrease in the time they spent looking at areas of their infant's face other than eyes or mouth ( $\mathrm{p}=.082)$ (Figure 1). Finally, an interaction between AOI and Group $(\mathrm{F}(2$, 222) $=4.176 ; \mathrm{p}=.017$ ) was also found. Regardless of infant age, although index and comparison group mothers spent a similar amount of time looking at their infant's eyes, the former spent more time compared to the latter looking at facial areas other than eyes or mouth ( $\mathrm{p}=.001)$, and marginally less time looking at their infant's mouth $(\mathrm{p}=.053)$ (Figure 2).

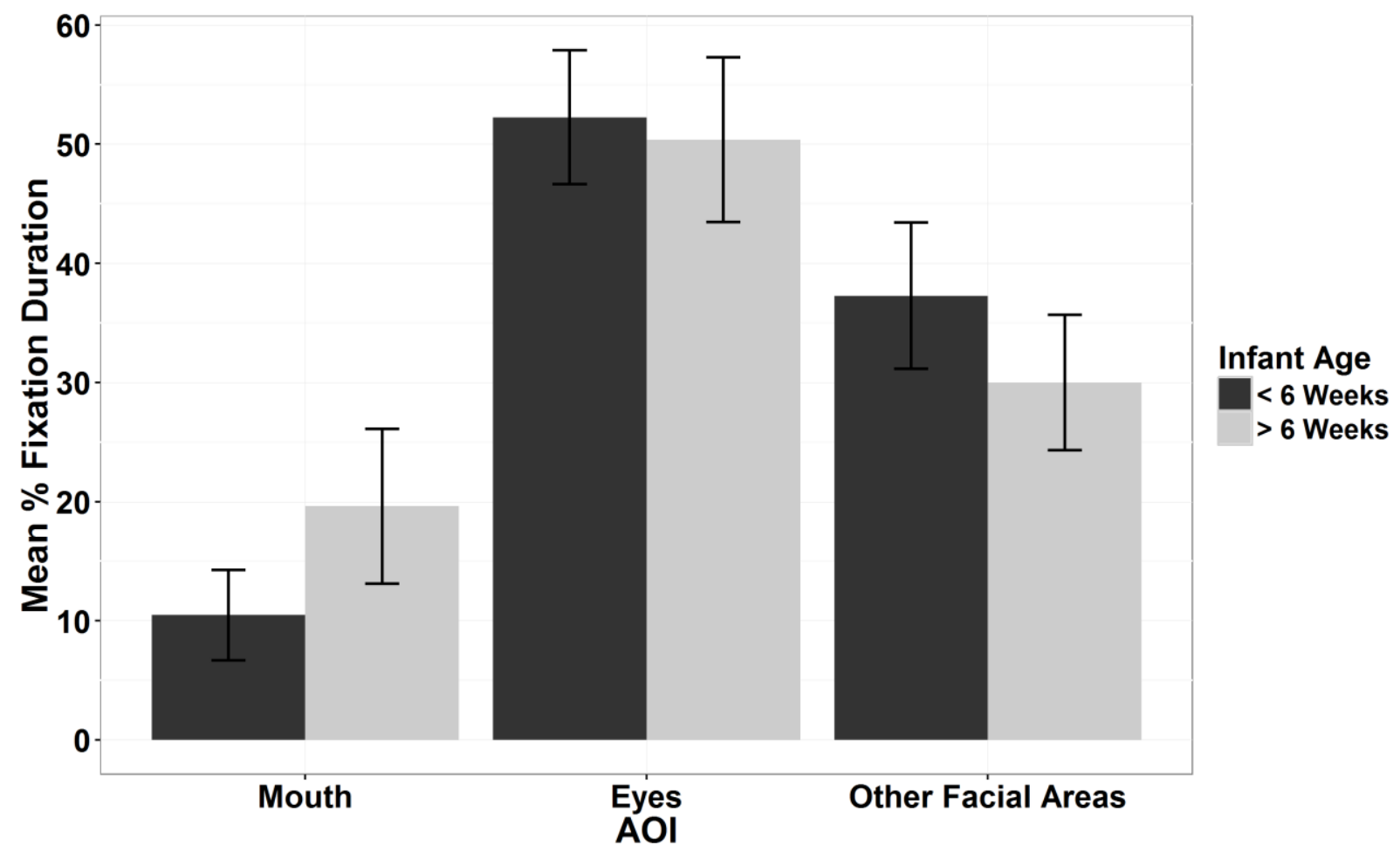

Figure 1. Fixation Duration according to Facial AOI, and Infant Age. Error bars denote standard errors. 


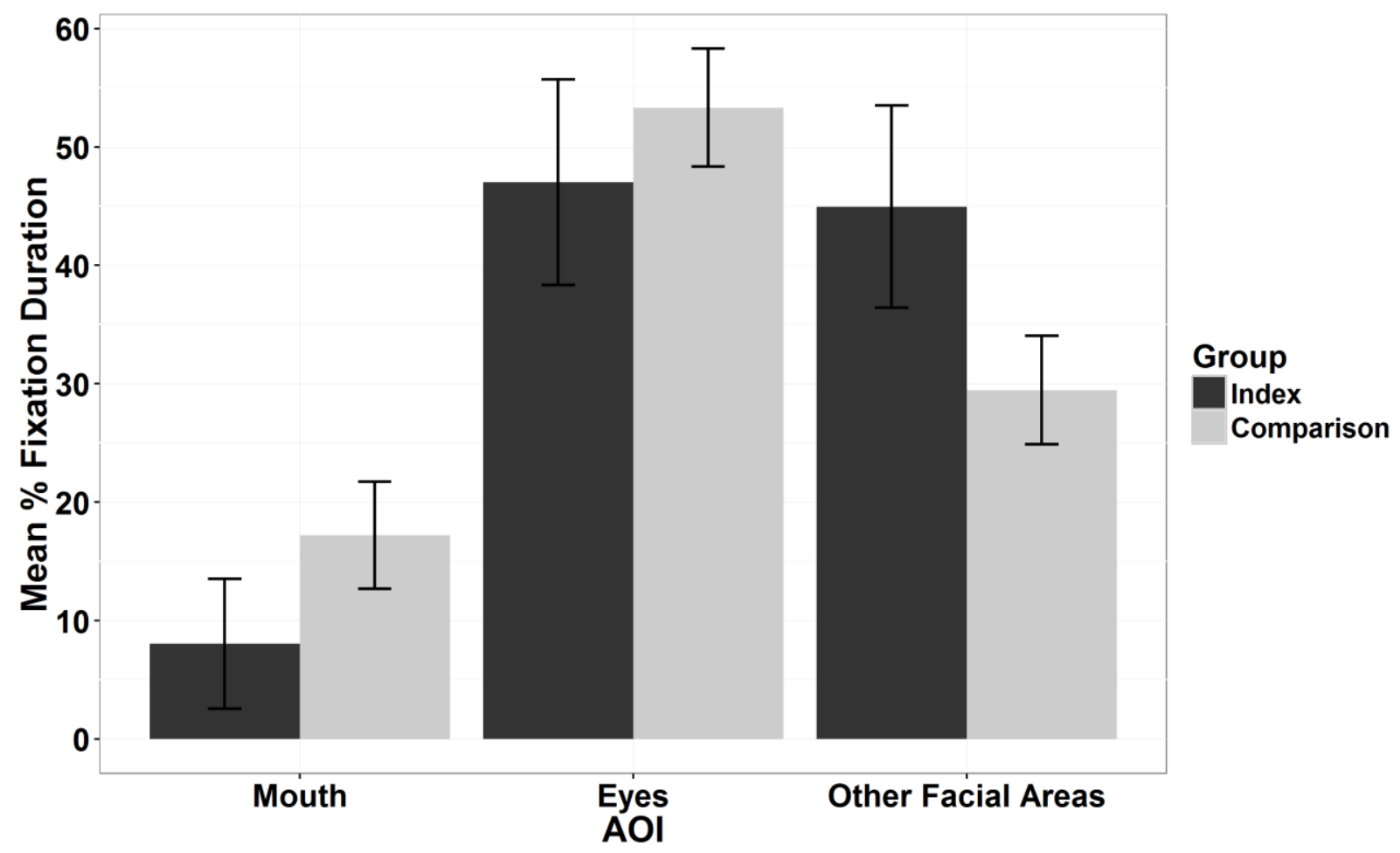

Figure 2. Fixation Duration according to Facial AOI, and Group. Error bars denote standard errors.

\section{Discussion}

Results from this study provide novel data concerning maternal gaze to infant faces during early naturalistic interactions. Three specific questions were addressed: (i) which areas of an infant's face are fixated on, during the first 9 weeks; (ii) how is gaze influenced by infant age, and particularly by the change from six weeks in social development; and (iii) how is gaze affected by disturbed infant facial configuration, represented here by cleft lip.

With regard to the first question, irrespective of infant age or cleft lip, mothers spent the vast majority of the interaction gazing at the face of their infant (looking at their body when not focusing on facial areas, and almost never completely looking away from the infant), fixating on their eyes more than the mouth or other facial areas. This result is in accordance with the fundamental bias towards eye fixation when viewing typical adult faces (Auyeung et al., 
2015; Klin, Jones, Schultz, Volkmar, \& Cohen, 2002). The maternal focus on the infant's eyes is important since it creates an interactive environment rich in the prototypical eyecontact cues that young infants both prefer (Batki et al., 2000; Johnson et al., 2015; Simion \& Di Giorgio, 2015) and capitalize on during early development (Farroni et al., 2007; Grossmann et al., 2008; Rigato et al., 2011). It also highlights the readiness of mothers to signal their availability to interact and capture their infant's attention, even during this early period when infants periodically break direct eye-contact (Stern, 1974). This result is particularly notable because, to our knowledge, it represents the first time that this maternal visual focus on the eye area of the infant's face during live naturalistic interactions has been reported. As noted by Leeb and Rejskind (2004), most studies on mother-infant eye contact have focused on maternal gaze to the infant's whole face, because of the difficulty of coding gaze shifts within such a small area, but the precision of eye-tracking technology allowed us to provide the first empirical account of maternal gaze preferences and patterns during live mother-infant interactions.

Regarding our second question, all mothers looked less at facial areas other than the eyes and mouth after six weeks than in earlier interactions. Further, although infant eyes consistently attracted more visual attention compared to the mouth, maternal gaze towards the mouth area increased over time, both for infants with and without cleft lip. The increase in maternal gaze to the infant's mouth after six weeks coincides with the increase at this time in the rate and range of infant communicative cues during face-to-face interactions (Lavelli \& Fogel, 2002; Trevarthen, 1979), including smiles, vocalizations and 'prespeech' mouth movements. This suggests that maternal gaze changed as an adaptation to the infant's growing social expressiveness, underlining the more general observation that parent-infant engagements are a dynamic, two-way process, with parents making intuitive adjustments that are sensitive to their infants' development (Papoušek \& Papoušek, 1995; Parsons et al., 2010). Consistent 
with the idea of maternal gaze adjusting to the infant's change to active communication is the fact that the shift observed brought maternal gaze into line with the pattern found during listening, rather than speaking, in adult interactions (Buchan et al., 2007; Paré et al., 2003). Adaptation to infant developmental shifts has been illustrated in changes in maternal speech to the infant within the first three months (Henning, Striano, \& Lieven, 2005), and in shifts in maternal gaze away from the infant's face after three-four months when infant prehension and vision improve (Sylvester-Bradley \& Trevarthen, 1978), but has not previously been documented for maternal gaze within the first 10 weeks.

Regarding the final question, the presence of a cleft significantly altered maternal gaze patterns: compared to mothers of typical infants, mothers of affected infants spent less time looking at their infant's face, in line with previous research (Murray et al., 2008), and more time looking at their infant's body. Further, although maternal gaze to the eyes was similar for infants with and without cleft lip across time, mothers of infants with a cleft gazed more than comparison group mothers towards facial areas other than the eyes or mouth, and gazed correspondingly less to the infant's mouth

The reduced gaze to the mouth of index group infants is contrary to our prediction, based on previous experimental research concerning gaze to static images, that increased maternal gaze towards the mouths of infants with cleft lip would be made at the expense of fixation on the eyes. The reasons for this difference in findings are not entirely clear. One possibility is that the two contexts within which gaze to faces with a cleft has been examined elicit different modes of response in observers. In experimental studies involving gaze to static images, participants are in the role of objective observers, free to gaze wherever they want, without behaviour-inhibiting social processes that might apply during in vivo social engagements, such as embarrassment or concern about behaving insensitively. Without such concerns, the likely novelty of the cleft may draw observers' attention to the affected mouth area, away 
from the eyes. Examination of responses to static faces by subjects who are familiar with cleft faces could elucidate this issue. An alternative explanation concerns the nature of the observers in the experimental vs. the current naturalistic interaction study. Participants in experimental studies have been unacquainted with the individuals whose faces they saw, whereas our study subjects were the parents of the infants with whom they were interacting. Surveys and qualitative studies show that parents may experience a range of responses following the birth of an infant with a cleft (Nelson, Glenny, Kirk, \& Caress, 2012). Thus, difficult emotions can be experienced, such as grief, or worry, as well as positive adjustment and feelings. More research is needed in this area, but parents' emotional responses might contribute to engagements with the infant, and therefore their gaze. It has also been suggested that a cleft lip might make it difficult for parents to interpret their infant's mouth activity (Field \& Vega-Lahr, 1984), and this too might explain their giving this facial area less attention than parents of unaffected infants. Finally, the set of intuitive parenting responses elicited by infant faces, as revealed in brain responses occurring within just 140 milliseconds (Parsons et al., 2013), might extend to gaze direction, which might not be mobilized in the same way when gazing at an infant with a cleft lip. Such intuitive responses occur out of conscious awareness, and may not be associated with any sense of distress or difficulty in responding to the infant.

Although a strength of this study was the novel use of eye-tracking technologies to study, in unprecedented detail, maternal gaze during live mother-infant interactions, and to do so in the first weeks of life when few data are available, a limitation was the small sample size available. Given this, and the novelty of the result, further replications on larger samples are warranted.

\section{Clinical Implications}


Regardless of its reason, our finding that, in the context of cleft lip, parents gaze less to the infant's mouth may be of clinical significance. Previous studies have found infants born with a cleft lip to show no temperamental difference, but are less communicative (Montirosso et al., 2012), and cooperative (Habersaat et al., 2013) during early interactions, while their mothers show decreased responsiveness and sensitivity to infant social behaviour (Field \& Vega-Lahr, 1984; Murray et al., 2008; Speltz, Goodell, Endriga, \& Clarren, 1994), negatively affecting later infant cognitive outcomes (Murray et al., 2008; Speltz et al., 2000; Wasserman \& Allen, 1985). All these studies have, however, focused on infants of at least 2 months of age, with no available data on earlier behaviours of mothers and infants with cleft lip. The results from our study indicate how mother-infant engagement might be affected by the presence of a cleft lip earlier than previously reported. Thus, even if the presence of a cleft lip did not alter maternal visual focus towards the eye area, the disruption of gaze to the infant's mouth, particularly after the onset of infant social expressiveness, might affect maternal fostering of early infant communicative cues. This relative maternal visual avoidance of the cleft area suggests new possible dimensions of parent-infant contacts that clinicians should be aware of, and that they could target in supporting the early relationship in these mother-infant dyads, for example by facilitating maternal awareness of the potential social significance of some infant mouth movements.

\section{Acknowledgements}

We thank Jane Sibley, Tina O’Neill, and the Spires Cleft Centre Team, for their help in recruitment to this study, and Scott Hodgins, from Acuity ETS Limited, for his support and guidance in the use of the eye-tracking glasses.

\section{Funding}


The study was funded by the Barclay Foundation, and the Cleft Research Development Fund of the Spires Centre Cleft Centre. Holly Rayson was supported by an MRC studentship (grant number: MR/J003980/1).

\section{References}

Arco, C. M. B., Self, P. A., \& Gutrecht, N. (1979). The effect of increased maternal visual regard on neonatal visual behavior. Journal of Clinical Child Psychology, 8(2), 117120.

Auyeung, B., Lombardo, M. V, Heinrichs, M., Chakrabarti, B., Sule, A., Deakin, J. B., Bethlehem, R. A. I., Dickens, L., Mooney, N., Sipple, J. A. N., Thiemann, P., BaronCohen, S. (2015). Oxytocin increases eye contact during a real-time, naturalistic social interaction in males with and without autism. Translational psychiatry, 5(2), e507.

Baron-Cohen, S. (1994). How to build a baby that can read minds: Cognitive mechanisms in mindreading. Cahiers de Psychologie Cognitive/Current Psychology of Cognition, 13(5), 513-552.

Batki, A., Baron-Cohen, S., Wheelwright, S., Connellan, J., \& Ahluwalia, J. (2000). Is there an innate gaze module? Evidence from human neonates. Infant Behavior and Development, 23(2), 223-229.

Benjamini, Y., \& Hochberg, Y. (1995). Controlling the false discovery rate: a practical and powerful approach to multiple testing. Journal of the Royal Statistical Society, 57(1), 289-300.

Bloom, K. (1974). Eye contact as a setting event for infant learning. Journal of Experimental Child Psychology, 17, 250-263.

Britton, H. L., Gronwaldt, V., \& Britton, J. R. (2001). Maternal postpartum behaviors and 
mother-infant relationship during the first year of life. Journal of Pediatrics, 138(6), 905-909.

Buchan, J. N., Paré, M., \& Munhall, K. G. (2007). Spatial statistics of gaze fixations during dynamic face processing. Social Neuroscience, 2(1), 1-13.

Cox, J. L., Holden, J. M., \& Sagovsky, R. (1987). Detection of postnatal depression: development of the 10-item Edinburgh Postnatal Depression Scale. British Journal of Psychiatry, 150, 782-786.

Delgado, C. E. F., Messinger, D. S., \& Yale, M. E. (2002). Infant responses to direction of parental gaze: A comparison of two still-face conditions. Infant Behavior and Development, 25(3), 311-318.

Farroni, T., Johnson, M. H., Menon, E., Zulian, L., Faraguna, D., \& Csibra, G. (2005). Newborns' preference for face-relevant stimuli: effects of contrast polarity. Proceedings of the National Academy of Sciences of the United States of America, 102(47), 1724517250.

Farroni, T., Mansfield, E. M., Lai, C., \& Johnson, M. H. (2003). Infants perceiving and acting on the eyes: Tests of an evolutionary hypothesis. Journal of Experimental Child Psychology, 85, 199-212.

Farroni, T., Massaccesi, S., Menon, E., \& Johnson, M. H. (2007). Direct gaze modulates face recognition in young infants. Cognition, 102(3), 396-404.

Ferrari, P. F., Paukner, A., Ionica, C., \& Suomi, S. J. (2009). Reciprocal face-to-face communication between rhesus macaque mothers and their newborn infants. Current Biology, 19(20), 1768-1772.

Field, T. M., \& Vega-Lahr, N. (1984). Early interactions between infants and their 
postpartum depressed mothers. Infant Behavior and Development, 7(4), 517-522.

Glocker, M. L., Langleben, D. D., Ruparel, K., Loughead, J. W., Gur, R. C., \& Sachser, N. (2009). Baby schema in infant faces induces cuteness perception and motivation for caretaking in adults. Ethology: formerly Zeitschrift fur Tierpsychologie, 115(3), 257263.

Gómez, J. C. (2009). Embodying meaning: insights from primates, autism, and Brentano. Neural networks, 22(2), 190-196.

Grossmann, T., Johnson, M. H., Farroni, T., \& Csibra, G. (2007). Social perception in the infant brain: Gamma oscillatory activity in response to eye gaze. Social Cognitive and Affective Neuroscience, 2(4), 284-291.

Grossmann, T., Johnson, M. H., Lloyd-Fox, S., Blasi, A., Deligianni, F., Elwell, C., \& Csibra, G. (2008). Early cortical specialization for face-to-face communication in human infants. Proceedings of the Royal Society B: Biological Sciences, 275(1653), 28032811.

Habersaat, S., Monnier, M., Peter, C., Bolomey, L., Borghini, A., Despars, J., Pierrehumbert, B., Müller-Nix, C., Ansermet, F., \& Hohlfeld, J. (2013). Early mother-child interaction and later quality of attachment in infants with an orofacial cleft compared to infants without cleft. The Cleft Palate-Craniofacial Journal, 50(6), 704-712.

Hains, S. M. J., \& Muir, D. W. (1996). Infant sensitivity to adult eye direction. Child Development, 67(5), 1940-1951.

Henning, A., Striano, T., \& Lieven, E. V. M. (2005). Maternal speech to infants at 1 and 3 months of age. Infant Behavior and Development, 28(4), 519-536.

Heo, M., \& Leon, A. C. (2010). Sample sizes required to detect two-way and three-way 
interactions involving slope differences in mixed-effects linear models. Journal of Biopharmaceutical Statistics, 20(4), 787-802.

Johnson, M. H., Dziurawiec, S., Ellis, H., \& Morton, J. (1991). Newborns’ preferential tracking of face-like stimuli and its subsequent decline. Cognition, 40(1-2), 1-19.

Johnson, M. H., Senju, A., \& Tomalski, P. (2015). The two-process theory of face processing: Modifications based on two decades of data from infants and adults. Neuroscience and Biobehavioral Reviews, 50, 169-179.

Klin, A., Jones, W., Schultz, R., Volkmar, F., \& Cohen, D. (2002). Visual fixation patterns during viewing of naturalistic social situations as predictors of social competence in individuals with autism. Archives of general psychiatry, 59(9), 809-816.

Kringelbach, M. L., Lehtonen, A., Squire, S., Harvey, A. G., Craske, M. G., Holliday, I. E., Green, A. L., Aziz, T. Z., Hansen, P. C., Cornelissen, P. L., Stein, A. (2008). A specific and rapid neural signature for parental instinct. PloS one, 3(2), e1664.

Landry, S. H., Smith, K. E., \& Swank, P. R. (2006). Responsive parenting: establishing early foundations for social, communication, and independent problem-solving skills. Developmental Psychology, 42(4), 627-642.

Lavelli, M., \& Fogel, A. (2002). Developmental changes in mother-infant face-to-face communication: Birth to 3 months. Developmental Psychology, 38(2), 288-305.

Leeb, R. T., \& Rejskind, F. G. (2004). Here's looking at you, kid! A longitudinal study of perceived gender differences in mutual gaze behavior in young infants. Sex Roles, 50(12), 1-14.

Leon, A. C., \& Heo, M. (2009). Sample sizes required to detect interactions between two binary fixed-effects in a mixed-effects linear regression model. Computational Statistics 
\& Data Analysis, 53(3), 603-608.

Meyer-Marcotty, P., Gerdes, A. B. M., Reuther, T., Stellzig-Eisenhauer, A., \& Alpers, G. W. (2010). Persons with cleft lip and palate are looked at differently. Journal of Dental Research, 89(4), 400-404.

Meyer-Marcotty, P., Gerdes, A. B. M., Stellzig-Eisenhauer, A., \& Alpers, G. W. (2011). Visual face perception of adults with unilateral cleft lip and palate in comparison to controls--an eye-tracking study. The Cleft Palate-Craniofacial Journal, 48(2), 210-216.

Montirosso, R., Fedeli, C., Murray, L., Morandi, F., Brusati, R., Perego, G. G., \& Borgatti, R. (2012). The role of negative maternal affective states and infant temperament in early interactions between infants with cleft lip and their mothers. Journal of Pediatric Psychology, 37(2), 241-250.

Murray, L., Fiori-Cowley, A., Hooper, R., \& Cooper, P. (1996). The impact of postnatal depression and associated adversity on early mother-infant interactions and later infant outcome. Child development, 67(5), 2512-2526.

Murray, L., Hentges, F., Hill, J., Karpf, J., Mistry, B., Kreutz, M., Woodall, P., Moss, T., Goodacre, T. (2008). The effect of cleft lip and palate, and the timing of lip repair on mother-infant interactions and infant development. Journal of Child Psychology and Psychiatry, 49(2), 115-123.

Nelson, P., Glenny, A. M., Kirk, S., \& Caress, A. L. (2012). Parents' experiences of caring for a child with a cleft lip and/or palate: A review of the literature. Child: care, health and development, 38(1), 6-20.

Papoušek, H., \& Papoušek, M. (1995). Intuitive parenting. In M. H. Bornstein (Ed.), Handbook of parenting, Vol. 2: Biology and ecology of parenting (pp. 117-136). CHAP, 
Hillsdale, NJ: Lawrence Erlbaum Associates, Inc.

Paré, M., Richler, R. C., ten Hove, M., \& Munhall, K. G. (2003). Gaze behavior in audiovisual speech perception: The influence of ocular fixations on the McGurk effect. Perception \& Psychophysics, 65(4), 553-567.

Parsons, C. E., Young, K. S., Mohseni, H., Woolrich, M. W., Thomsen, K. R., Joensson, M., Murray, L., Goodacre, T., Stein, A., Kringelbach, M. L. (2013). Minor structural abnormalities in the infant face disrupt neural processing: A unique window into early caregiving responses. Social Neuroscience, 8(4), 268-274.

Parsons, C. E., Young, K. S., Murray, L., Stein, A., \& Kringelbach, M. L. (2010). The functional neuroanatomy of the evolving parent-infant relationship. Progress in Neurobiology, 91(3), 220-241.

Parsons, C. E., Young, K. S., Parsons, E., Dean, A., Murray, L., Goodacre, T., Dalton, L., Stein, A., Kringelbach, M. L. (2011). The effect of cleft lip on adults' responses to faces: Cross-species findings. PloS one, 6(10), e25897.

Rayson, H., Parsons, C. E., Young, K. S., Goodacre, T., Kringelbach, M. L., Bonaiuto, J. J., McSorley, E., Murray, L. (in press). Effects of infant cleft lip on adult gaze and perceptions of "cuteness." The Cleft Palate-Craniofacial Journal.

Rigato, S., Menon, E., Johnson, M. H., Faraguna, D., \& Farroni, T. (2011). Direct gaze may modulate face recognition in newborns. Infant and Child Development, 20(1), 20-34.

Robson, K. S. (1967). The role of eye-to-eye contact in maternal-infant attachment. Journal of Child Psychology and Psychiatry, 8(1), 13-25.

Senju, A., \& Csibra, G. (2008). Gaze following in human infants depends on communicative signals. Current Biology, 18(9), 668-671. 
Simion, F., \& Di Giorgio, E. (2015). Face perception and processing in early infancy: inborn predispositions and developmental changes. Frontiers in Psychology, 6, 969.

Speltz, M. L., Endriga, M. C., Hill, S., Maris, C. L., Jones, K., \& Omnell, M. L. (2000). Brief report: Cognitive and psychomotor development of infants with orofacial clefts. Journal of Pediatric Psychology, 25(3), 185-190.

Speltz, M. L., Goodell, E. W., Endriga, M. C., \& Clarren, S. K. (1994). Feeding interactions of infants with unrepaired cleft lip and/or palate. Infant Behavior and Development, 17(2), 131-139.

Stern, D. N. (1974). Mother and infant at play: The dyadic interaction involving facial, vocal, and gaze behaviors. In M. Lewis \& L. A. Rosenblum (Eds.), The Effect of the Infant on its Caregiver (pp. 187-214). New York, NY: Wiley-Interscience.

Stern, D. N. (1977). The First Relationship. Cambridge, MA: Harvard University Press.

Sylvester-Bradley, B., \& Trevarthen, C. (1978). Baby talk as an adaptation to the infant's communication. In N. Waterson \& C. Snow (Eds.), The Development of Communication (pp. 75-92). Chichester, UK: John Wiley \& Sons, Ltd.

Symons, L. A., Hains, S. M. J., \& Muir, D. W. (1998). Look at me: Five-month-old infants' sensitivity to very small deviations in eye-gaze during social interactions. Infant Behavior and Development, 21, 531-536.

Tobii Technology AB. (2014). Tobii Studio Version 3.3.0 User Manual. Danderyd (Sweden): Tobii Technology AB.

Trevarthen, C. (1979). Communication and cooperation in early infancy: a description of primary intersubjectivity. In M. Bullowa (Ed.), Before Speech: The Beginning of Interpersonal Communication (pp. 321-348). Cambridge, UK: Cambridge University 
Press.

Wasserman, G. A., \& Allen, R. (1985). Maternal withdrawal from handicapped toddlers. Journal of Child Psychology and Psychiatry, 26(3), 381-387.

Yamamoto, R., Ariely, D., Chi, W., Langleben, D. D., \& Elman, I. (2009). Gender differences in the motivational processing of babies are determined by their facial attractiveness. PloS one, 4(6), e6042. 